\title{
Empirical Research on Relationship among Urbanization, FDI and Economic Growth: A Case of China from1999 to 2015
}

\author{
Yan-yang $\mathrm{Gao}^{1}$, Shuai Shao ${ }^{2}$ \\ ${ }^{1}$ Electrical and Information College, Jinan University, Zhuhai, China. \\ ${ }^{2}$ Finance Department of International Business School, Jinan University, Zhuhai, China. \\ Correspondence: Yan-yang Gao, Electrical and Information College, Jinan University, Qianshan Road 206\#, Zhuhai \\ City, Guangdong Province, Post No. 519070, China.
}

Received: April 11, 2016

doi:10.11114/aef.v3i3.1537
Accepted: April 27, $2016 \quad$ Available online: May, 2016

URL: http://dx.doi.org/10.11114/aef.v3i3.1537

\begin{abstract}
In China's rapid economic growth and significant increase in the process of urbanization, a large number of foreign direct investment may play an impeccable role. We establish a Vector Auto-Regressive (VAR) model and make empirical research by using foreign direct investment, the urbanization and economic growth of quarterly data in China from 1999 to 2015. Then we use the unit root test, cointegration test, error correction model and Granger causality test to analyze three factors, and use impulse response function diagrams to analyze the relationship among FDI, urbanization and economic growth. The empirical results show that there is a cointegration relationship among FDI, urbanization and GDP. FDI and economic growth are granger causality each other, urbanization is the granger cause of FDI. Meanwhile, economic growth is the granger cause of urbanization. In the long run, improve domestic infrastructure construction and absorb foreign capital into domestic capital market are helpful to drive China's economic growth. The influence of urbanization on foreign investment continues to rise, meaning that urban development has pull effect to foreign investment. The departments concerned should encourage entrance of foreign capital to provide appropriate for the convenience of various kinds of production factors. At the same time, government should improve national awareness to stimulate consumption of foreign capital. What is more, we should accelerate the speed of urbanization, increase the intensity of financial expenditure to urbanization and increase the domestic economy by introducing foreign capital and city development.
\end{abstract}

Keywords: FDI, Vector Auto Regressive, population urbanization, Granger causality

\section{Introduction}

Since reforming and opening up, China's economic grows rapidly. China's gross domestic product (GDP) grows from 365 billion yuan ( $\$ 216.8$ billion)in 1978 to63.6139 trillion yuan ( $\$ 10.3558$ trillion) in 2014. GDP, which is one of China's economic development main indicators, has undergone several stages: it reached over 100 billion yuan in 1956, over 500 billion yuan in 1982, over 1 trillion yuan, which is 1.0309 trillion yuan (\$298.6 billion) in 1986, over 5 trillion yuan to 6.113 trillion yuan ( $\$ 732$ billion) in $1995,11.027$ trillion yuan ( $\$ 1.3323$ trillion) in 2001, over 50 trillion yuan, to 53.4123 trillion yuan in 2012, and finally reached 63.6139 trillion yuan in 2014. In the aspect of urbanization, China's urbanization rate is only $36 \%$ in 2000 , and rise over $50 \%$ to $51.27 \%$ in 2011 for the first time. Since 2013, China continue clinging to open and inclusive regional cooperation through the One Belt and One Road project and the Asian Infrastructure Investment Bank, and reduce restrictions on foreign investment sharply. According to statistics, the country set up 23778 foreign-invested enterprises from January to December in 2014, with year-on-year growth of 4.4\%; The amount of actual use of foreign capital is $\$ 119.56$ billion (736.37 billion yuan), with year-on-year growth of $1.7 \%$. Economic also grows rapidly. In the process of economic growth and fast urbanization of China, introducing of large amount of FDI may have played an important role.

Twenty-first Century is a great era of innovation and creation, competition and cooperation, conflict and integration. Large-scale capital flows, continuous innovation of technology and knowledge, the tendency of practice to benefit of micro economic entities, more open and free market economic system and other factors constitute the complicated connotation and the extension of economic globalization and they are intertwined to a country's social, economic, cultural and other produce complex, multiple, both advantages and disadvantages of the impact and constitutes the 
development factor of urbanization in China. It is the huge international background of China's rapid economic growth.Foreign investment will produce certain effect for urbanization and economic growth in the developing world, there are many scholars both at home and abroad in recent years research on these aspects, but most of the research is to explore the FDI and urbanization or FDI and economic growth, and more for the use of a small region of the data analysis of the developing countries.In this paper, by using the quarterly data of China, FDI, urbanization and economic growth's relationship between the three common vector autoregression equation, we research the relationship which further enrich the foreign investment in developing countries the relationship between urbanization and economic growth. The study on the utilization of foreign direct investment promote China and other cities in developing countries construction and rural surplus labor force transfer and the relatively backward areas of urbanization and economic development can play a referential significance.

The relationship among FDI, urbanization and economic growth, has always been the focus controversial topic of the scholars home and abroad in terms of economic and social research. In terms of the relationship between urbanization and FDI, Kasarda, Crenshaw, Hein and others believe that FDI can make a positive effect on urbanization in the developing world. Ling Wang set up vector auto-regression model based on relevant data of urbanization rate and real per capital GDP in 1978-2009 in Shanghai, and finally come to a conclusion that the effect of economic growth to population urbanization is relatively strong, while the effect of development of urbanization to economic growth is not obvious. Clark(1998) suppose that FDI created employment opportunities for developing countries, promote the industrial structure adjustment and labor transfer in developing countries, further accelerate its urbanization process. Direct study of the relationship between FDI and the urbanization is just a few, but most of them gets to the conclusion that there is positive relationship between these two aspects.

In terms of urbanization and economic growth, studies about their relationship have stayed for a long time. Berry (1965), using principal component analysis method to analyze the cross-section data of 95 countries, revealed correlation relationship between urbanization and economic growth. North (1975) proposed the linear experience relationship equations of them. Domestic related research is also rich. Yi-Xing Zhou (1982) reveals their relationship is logarithmic curve relationship. Yao-bin Liu (2006) shows that their relationship is mutual positive, and render time using co-integration relationship test to make empirical analysis. The research result of Zhi-heng Yang and Xue-er Yang (2012) shows that economic growth promotes urbanization, while the role of urbanization on economic growth is not obvious. At present, the mainstream direction of research is the promoting effect of urbanization on economic growth.

In terms of the relationship between FDI and economic growth, after the World War II in the 20th century, the wave of globalization swept across the world, the multinational companies made a large number of transnational investment, and western scholars made a lot of research of investing activities of multinational companies. Vernon (1965) proposed the product life cycle theory. Dunning (1977) made the theory of international production compromise. After that, a lot of scholars studied the relationship between FDI and economic growth from the perspective of empirical research. Volk Bornshier, Chirstopher Chase and Richard Rubinso (1978) found that FDI promotes the economy's long-term growth, but not obvious in the short term, after researching the use of FDI in 76 developing countries. Borensztein, De Gregorio and Lee used 1970-1989 data in 69 developing countries and found that FDI can make a positive contribution to economic growth, its contribution rate to economic growth is more than that of domestic investment. Mello(1999) researched comprehensive effect of FDI and thought that FDI promotes the economic growth through capital accumulation and technology spillover using the panel data. Domestic related research results have also made a great progress. Jin-ping Zhao(2001) analyzed the relationship between FDI and economic growth model from the angle of quantitative and qualitative through establishing the model of FDI and economic growth. Ding-Xiang Mao (2005) found that FDI promotes the accumulation of capital in our country effectively, and further promotes the economic growth through empirical study. Guo-hsi Bao and Zhi Luo (2009) believe that the positive effect of technology factors in FDI on economic growth is significantly greater than domestic capital. Chun-gen Chen, Qin Hu (2012) found that FDI has a positive effect to China's economic growth in the long term, while negative effect in the short term through comparing the BRIC countries. Some scholars bother whether FDI can promote economic growth, but most of the research conclusion affirms the positive role of FDI on economic growth.

This paper put the FDI and urbanization into the analysis framework at the same time and analyze of the mutual influence of FDI and urbanization to the economic growth on the basis of previous studies. With China's national quarterly data as example, we use the time series data of the first quarter in 1999 to the third quarter in 2015 to test and analyze the equilibrium relationship of these three factors based on the VAR model by using unit root test, co-integration analysis, impulse response function and causality test.

\section{Main research methods}

\subsection{Model Specification}

In this paper, we establish a VAR model and make empirical research by using foreign direct investment, the 
urbanization and economic growth of quarterly data in China. Structure modeling method can make use of economic theory to describe the relationship among the variables, but economic theory can't be provide strict definition of dynamic relationship among the variables. The endogenous variable may also appear on the right and left sides of the equation at the same time, it makes the estimation and inference of problems become complicated. In order to solve this problem, thus produced the multivariate modeling methods of the structure. Vector autoregressive model is such a unstructured multivariate model equation. In addition to overcoming the limitations of traditional simultaneous equations subject to economic theory, the VAR model can also be causal relationship between variables inspection and make impulse response function to analyze the relationship of variables. Based on the analysis of VAR model, this paper carries out co integration analysis, impulse response analysis and Grainger causality test in turn.

Vector autoregression often used to predict the time series system and random dynamic disturbance effect on variable system. The model avoids the modeling method of the structural modeling method, which needs to be modeled on every endogenous variable in the system. The mathematical expression for the general VAR model is:

$$
y_{t}=A_{1} y_{t-1}+A_{2} y_{t-2} \cdots+A_{p} y_{t-p}+B_{1} x_{t}+B_{2} x_{t-2} \cdots B_{r} x_{t-r}+\varepsilon_{t}
$$

Where, $y_{t}$ is an $m \mathrm{~d}$ endogenous vector variable, $x_{1}$ is an $d$ d exogenous variables, $A_{1}, A_{2}, \cdots, A_{p}$ and $B_{1}$, $B_{2}, \cdots, B_{r}$ are the parameter matrix to be estimated. Endogenous variables and exogenous variables respectively $\mathrm{p}$ and $\mathrm{r}$ order lag, $\varepsilon_{t}$ is the random disturbance, its elements with time can be related to each other, but not with their own lag values and models related to the right of the variables.

\subsection{Johanson cointegration test}

Cointegration, is the existence of a common stochastic trend. The cointegration test is aim to determine whether a linear combination of a group of nonstationary series is a stable equilibrium relationship, a special case of spurious regression is two time series trend components of the same at this time may use this common trend corrected to make the regression of reliable. By co-integration delivered a long-term equilibrium relationship, if you can view with separate stochastic trend between several variable to find a reliable connection, then introduced the "relatively stable" to adjust the model, unit root stochastic trends can be excluded, known as the error correction model.

Johanson (1995) cointegration test is a test method based on VAR model, it also can be directly applied to multivariate cointegration test. Johannson cointegration test can not be done in a independent test, but a continuous inspection process according to different values. Johannson method provides two testing methods to verify the number of cointegration relationship, trace inspection and characteristic value respectively. The Trace statistic and Maximal Eigenvalue statistics can be used to test the number of vector cointegration relationship, the two statistics respectively defined as:

Trace statistic

$$
\lambda_{\text {trace }}=-T \sum_{i=r+1}^{k} \ln \left(1-\hat{\lambda}_{i}\right), r=0,1, \cdots, n-1
$$

Maximal Eigenvalue statistic

$$
\lambda_{\max }=-T \ln \left(1-\hat{\lambda}_{r+1}\right), r=0,1, \cdots, n-1
$$

Where $\hat{\lambda}_{i}$ refers to the characteristic root estimate var equation matrix, $\mathrm{T}$ is the effective sample size.

\subsection{Impulse response function analysis}

In practical application, because the VAR model is a theoretical model, it does not need to make any a priori constraint on the variables, so in the analysis of VAR model, often do not analyze the impact of changes in a variable to another variable how, but the analysis of an error change, or subject to a certain impact model of system dynamic effects, said this analysis method called impulse response analysis. The basic idea of the impulse response function is to consider how the influence of the disturbance term is propagated to each variable.

\section{Empirical Study}

\subsection{Data sources and processing}

In order to study the relation between foreign direct investment, urbanization rate and economic growth, this paper uses 
China's urbanization rate data(URB), foreign direct investment(FDI) and economic growth(GDP) variable for analysis. The content of the urbanization level is very rich, and different disciplines have different definition or measure of urbanization. For example, the urban population, urban land proportion, urban fiscal spending, Industry population proportion. This paper considers that a major characteristic of urbanization is the population aggregation from rural to urban. Therefore this article selects proportion of urban population to total population to measure urbanization level. Economic growth also has a lot of measures, this article selects gross domestic product (GDP) represents the economic growth, and through the price deflator, adjusted for price level in 1999. The sources of data are used to China's national bureau of statistics Considering the validity and availability of data, this paper uses the data of the time span for the first quarter of 1999 to 2015 in the third quarter. Due to the natural logarithm of time series data transformation will not change the characteristics of the data, but it can make the data trend linearization, and to a certain extent, to eliminate the heteroscedastic phenomenon caused by the time series, so based on the empirical analysis using the variables for numerical, respectively for $\operatorname{lnFDI}, \mathrm{URB}$, lnGDP, due to the urbanization rate is the percentage, therefore not desirable logarithmic. Figure 1 is shown that the three variables of time sequence diagram.

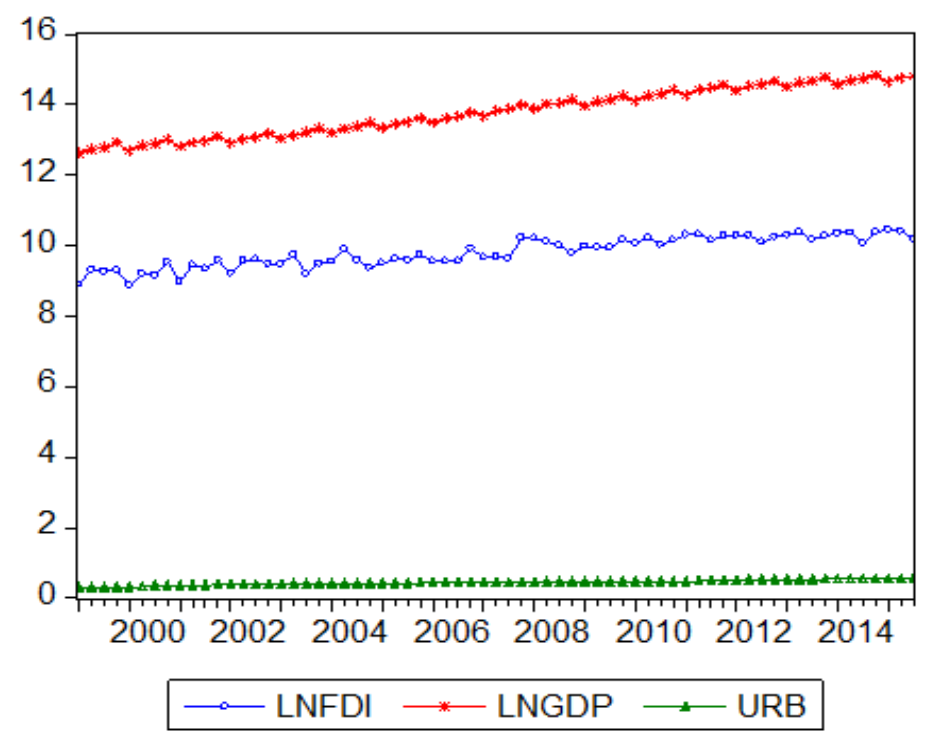

Figure.1 Time sequence diagram of three variables

\subsection{ADF unit root stationarity test}

Most of the macro variable data are non-stationary variables. Use the non-stationary data analysis is likely to make a lot of goodness of fit $R^{2}$, the lower the DW statistics, and the model coefficients shows very strong significance. The result of this is usually spurious regression. In the case of spurious regression, the model of the coefficient estimates, and other related statistics are not reliable, the nature of reason is that the traditional statistics estimate is not in the correct convergence, related statistic estimation and statistical inference also not have credibility. Therefore, in order to ensure that the unbiasedness and effectiveness of regression results, stationarity of various variables are analyzed before VAR model set up. This article uses the ADF unit root test to judge the Stability of the variables, the test results are shown in Tab.1. In the inspection type, $\mathrm{p}$ is lag order, $\mathrm{c}, \mathrm{t}$, respectively existing in the inspection relating to intercept and time trend, D said before the variables in the first-order difference sequence.

Tab.1 Augmented Dickey-Fuller Test Equation

\begin{tabular}{ccccccc}
\hline time series & $\begin{array}{c}\text { Test type (c } \\
\text { t p) }\end{array}$ & $\begin{array}{c}\text { ADF-test } \\
\text { staticstic }\end{array}$ & $\begin{array}{c}1 \% \\
\text { level }\end{array}$ & $\begin{array}{c}5 \% \\
\text { Level }\end{array}$ & $\begin{array}{c}10 \% \\
\text { level }\end{array}$ & $\begin{array}{c}\text { Whether } \\
\text { stationary }\end{array}$ \\
\hline lnFDI & (c t 1) & -1.592469 & -3.534868 & -2.906923 & -2.591006 & Non-stationary \\
URB & (c t 1) & -1.437791 & -3.534868 & -2.906923 & -2.591006 & Non-stationary \\
lnGDP & (c t 1) & -0.708501 & -3.534868 & -2.906923 & -2.591006 & Non-stationary \\
DlnFDI & (c t 0) & -13.91123 & -3.534868 & -2.906923 & -2.591006 & Stationary \\
DURB & (c t 1) & -4.933467 & -3.536587 & -2.907660 & -2.591396 & Stationary \\
DlnGDP & (c t 1) & -8.870031 & -3.536587 & -2.907660 & -2.591396 & Stationary \\
\hline
\end{tabular}


As shown in Tab.1 test results can be seen that at 1\%, 5\%, 10\% significant level, the sequence lnFDI, lnGDP and URB accept that time series exists unit root hypothesis, so these three time series is non-stationary. we need to do the further ADF unit root test on the first order difference sequence -- DlnFDI, DlnGDP and DURB. Test results show that the sequence Dlnfdi Dlngdp and Durb is stationary sequence under the $1 \%$ significant level. Because $\operatorname{lnFDI}$, lnGDP and URB sequence all have a unit root, not a stationary sequence, and the first-order difference sequence is stationary, therefore, we cannot use the ordinary regression methods to do the correlation test, it should be used co-integration test method.

\subsection{Cointegration analysis}

Cointegration means common stochastic trend of time series. a common stochastic trend, the purpose of the co-integration test is to determine a set of non-stationary sequence of whether there is a stable equilibrium relationship between linear combination. In order to further analysis of FDI, the long-term equilibrium relationship between urbanization and economic growth, analyses co-integration test for each variable. Cointegration definition for the first time in the Granger (1981) proposed in this study, it has rich meanings in economics, which characterizes the associated with the long-term equilibrium relationship between economic variables. The above unit root test proved that the three variables are first-order single whole shows lnfdi, lnGDP, urb pairs exist cointegration relationship, so the Johannson co-integration analysis of cointegration test on three variables. Results are shown in Table 2.

Table. 2 Unrestricted Cointegration Rank Test (Trace)

\begin{tabular}{ccccc}
\hline $\begin{array}{c}\text { Hypothesized } \\
\text { No. of CE }(\mathrm{s})\end{array}$ & Eigenvalue & $\begin{array}{c}\text { Trace } \\
\text { Statistic }\end{array}$ & $\begin{array}{c}0.05 \\
\text { Critical Value }\end{array}$ & Prob. $^{* *}$ \\
\hline None $^{*}$ & 0.323361 & 38.73964 & 29.79707 & 0.0036 \\
At most 1 & 0.181139 & 13.74009 & 15.49471 & 0.0903 \\
At most 2 & 0.014739 & 0.950293 & 3.841466 & 0.3296 \\
\hline
\end{tabular}

Trace test indicates 1 cointegrating eqn(s) at the 0.05 level

* denotes rejection of the hypothesis at the 0.05 level

Johannson cointegration test found that trace statistics of 38.73964 is greater than the critical value of 29.79707 , under the $5 \%$ significant level or at the $5 \%$ significant level rejected the null hypothesis does not exist co-integration equation, the whole equation shows that there are 3 collaborators. As a result, FDI, urbanization, there is a long-term equilibrium relationship between economic growth.

\subsection{The choice of lag period in VAR model}

When choosing order after $\mathrm{p}$, on the one hand, want to make the lag order is enough big, in order to complete the reaction dynamic characteristics of the constructed model, but on the other hand the lag order number, the greater the need to estimate the parameters of the more, the model of the degrees of freedom is reduced.

To set the order of the VAR model, in the Eviews get five evaluation value of the statistic. The results are shown in table 3 .

Table 3. VAR Lag Order Selection Criteria

\begin{tabular}{ccccccc}
\hline Lag & LogL & LR & FPE & AIC & SC & HQ \\
\hline 0 & 141.7479 & NA & $2.81 \mathrm{e}-06$ & -4.269167 & -4.168810 & -4.229570 \\
1 & 352.9158 & 396.3459 & $5.59 \mathrm{e}-09$ & -10.48972 & -10.08829 & -10.33133 \\
2 & 380.1877 & $48.66975^{*}$ & $3.19 \mathrm{e}-09^{*}$ & $-11.05193^{*}$ & $-10.34943^{*}$ & $-10.77475^{*}$ \\
\hline
\end{tabular}

Five evaluation indexes in the analysis report 3 think should build VAR (2) model, this article established VAR (2) model is established.

\subsection{Establishment of the VAR model}

To illustrate the relationship among urbanization, economic growth and FDI, and discuss how these three variables influence each other, we establish the VAR model to research dynamic relationship among the three variables. According to Tab. 3, the order of VAR model is determined to be 2, and the VAR (2) model is as follow: 


$$
\left[\begin{array}{c}
\ln F D I \\
\ln G D P \\
U R B
\end{array}\right]=\left[\begin{array}{ccc}
0.0742 & -0.2342 & 0.5160 \\
-0.0208 & 0.4652 & 0.1159 \\
-0.0009 & -0.0011 & 1.3928
\end{array}\right] \times\left[\begin{array}{c}
\ln F D I \\
\ln G D P \\
U R B
\end{array}\right]_{-1}+\left[\begin{array}{ccc}
-0.1064 & 0.8140 & -0.4611 \\
0.2049 & 0.3396 & 0.6375 \\
0.0004 & 0.0007 & -0.4554
\end{array}\right] \times\left[\begin{array}{c}
\ln F D I \\
\ln G D P \\
U R B
\end{array}\right]_{-2}\left[\begin{array}{c}
2.1573 \\
0.5993 \\
-0.0441
\end{array}\right]
$$

Where $R_{\ln F D I}^{2}=0.866473 ，$ Adj. $R_{\ln F D I}^{2}=0.852660 ， R_{\ln G D P}^{2}=0.981349 ， \quad$ Adj. $R_{\ln G D P}^{2}=0.979419$,

$R_{U R B}^{2}=0.997263, \operatorname{Adj} . R_{U R B}^{2}=0.996980$.

In general, most of the estimated coefficients of three VAR equations are statistically significant, and only a few are not significant. Statistics analyzed by Eviews5.0show that fitting degree of the equation of is high, suggesting that joint explain ability of variables is strong.

From VAR (2) model above, we can find that, for foreign investment, GDP growth in short term has a negative effect on foreign investment growth and the improvement of urbanization rate has a positive impact on foreign investment. With time passing by, the influence of economic growth to foreign investment is becoming positive. For economic growth, improvement of FDI has negative effects on economic growth, the ascension of urbanization rate has positive effects on economic growth in the short term. When it comes to urbanization, accelerate or retard of economic growth and foreign investment cannot increase current urbanization level. As time goes by, movement in economic growth and foreign investment to the influence of urbanization is gradually obvious. Pull effect of urbanization movement on its own is most obvious in the first period.

\subsection{Granger causality test}

We can obtain a long-term equilibrium relationship existing among FDI, urbanization and economic growth by co-integration relationship test, while for the direction remains to be further tested. In 1969, Granger put forward a method to test causal relationship among variables that is testing whether the lag variable of a variable is affected by lag variables of others, if so, then we can say they have Granger causality. Therefore, we make Granger causality test of three non-stationary time series. The regression model is as follow:

$$
\begin{aligned}
& y_{t}=\sum_{i=1}^{k} \alpha_{i} y_{t-i}+\sum_{i=1}^{k} \beta_{i} x_{t-i}+\mu_{1 t} \\
& x_{t}=\sum_{i=1}^{l} \gamma_{i} x_{t-i}+\sum_{i=1}^{l} \lambda_{i} y_{t-i}+\mu_{2 t}
\end{aligned}
$$

Where, assuming white noise $\mu_{1 t}$ and $\mu_{2 t}$ irrelevant. $\mathrm{K}$ and 1 are the largest lags. We took a lag phase 2 for Granger causality test in this paper, and the results are shown in Tab.4.

Table 4. Results of Granger causality test (lag:2)

\begin{tabular}{lccc}
\hline Null Hypothesis: & Obs & F-Statistic & Probability \\
\hline LNGDP does not Granger Cause LNFDI & 65 & 20.5556 & $1.6 \mathrm{E}-07$ \\
LNFDI does not Granger Cause LNDP & & 3.95197 & 0.02442 \\
\hline URB does not Granger Cause LNFDI & 65 & 7.12777 & 0.00167 \\
LNFDI does not Granger Cause URB & & 0.60511 & 0.54931 \\
\hline URB does not Granger Cause LNGDP & 65 & 0.30216 & 0.74034 \\
LNGDP does not Granger Cause URB & & 3.20187 & 0.04773 \\
\hline
\end{tabular}

As shown in Tab.4, under the 5\% significant level, there is two-way causality between FDI and economic growth. It can be seen that the improvement of urbanization level can attract more foreign investment, and the influx of foreign investment can quicken population transfer, promote industry clustering, and accelerate the process of urbanization. Under the 5\% significant level, the urbanization and the foreign investment is only a one-way causal relationship between, the urbanization is the granger reason of foreign investment, but the foreign investment is not the granger 
cause of urbanization. Under the 5\% significant level, the results show that economic growth is the granger cause of urbanization, but there is no granger causality relationship between urbanization and economic growth.

\subsection{Impulse response function analysis}

Cointegration analysis just shows whether there is a long-term equilibrium relationship in variables. But if we want to know how each variable unit changes cause the disturbance of the whole system by their internal relations, and comprehensive response of variables to the disturbance, we need make impulse response function analysis of the relationship among lnfdi, urb and lngdp through VAR model. Fig. 2 is the impulse response function curve based on VAR (2) model. It can visually depict the dynamic interaction and effect in variables. The horizontal axis represents back periods, and we set it as 25 years. The solid line shows the response function curve and two dotted line represents confidence belt of two times standard deviation.

Response to Cholesky One S.D. Innovations \pm 2 S.E.
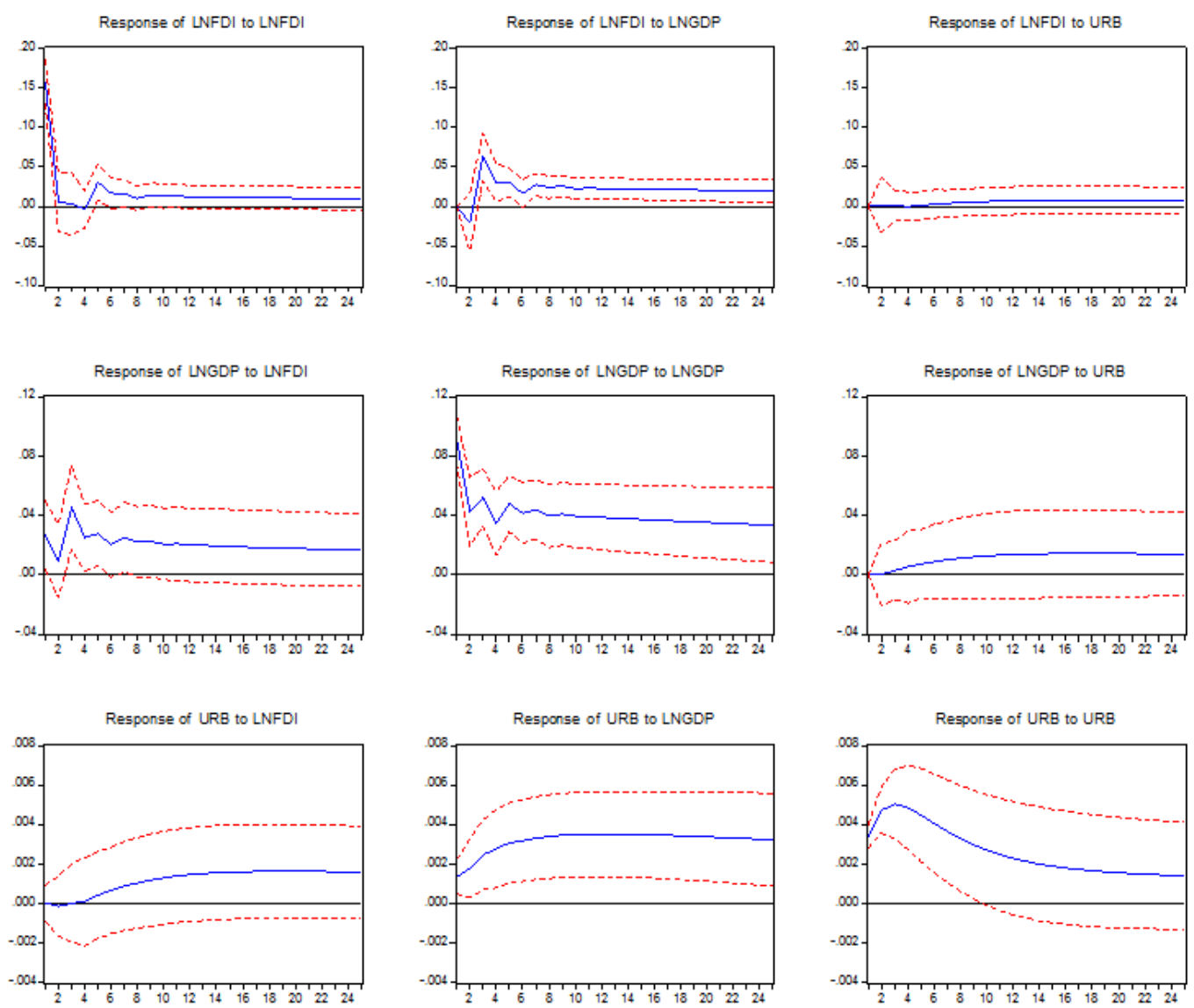

Figure 2.

As shown in Fig.2, we can tell from the impulse response function diagram of impact of economic growth on foreign investment that, when giving a shock to foreign direct investment, there will be a negative response after the first two period, and a rise to the biggest positive response point on the third stage, then a decrease until the convergence at the 7th period. It means that the economic growth does not promote the growth of foreign investment at first, but make it a downward trend instead.

In contrast, there is no negative effects of foreign investment on economic growth. We can see that, the impact of foreign investment on economic growth is not on the rise initially.

For the influence of foreign investment on urbanization, after exerting a shock on urbanization in the first period, there is not significant change in the first 3 phases, and a drastic growth after stage 4. It can be seen from the rising trend of foreign investment to urbanization that foreign investment has a positive influence on the level of urbanization.

\section{Conclusions}

We use quarterly data of foreign direct investment, urbanization and economic growth in China from 1999 to 2015 to 
make empirical analysis and use the unit root test, co-integration test, error correction model and Granger causality test to analyze three factors. We also use impulse response function method and finite difference decomposition method for empirical analysis of the relationship among FDI, urbanization and economic growth in China.

After validation of the model, we can get the following results: under the 5\% significant level, there is a two-way causality between FDI and economic growth. The improvement of urbanization can attract more foreign investment, and the influx of foreign investment can quicken the transfer of population, promote the industry clustering, and accelerate the process of urbanization. Moreover, urbanization is the granger reason of foreign investment.

As the growth of FDI, it does not promote FDI in the early period, but a downward trend. This may be because at the beginning, the government introduces a series of economic protection policies to protect domestic enterprises and capital. They exert restrictions on foreign capital, while as the stable trend of the economic, government releases the restriction on foreign investment, increasing the FDI. Therefore, if we want to make economic grow better and faster, we should reduce restrictions on foreign investment, at the same time, in order to prevent the impact of foreign capital introduction to domestic industries, the government should use policies to guide the investment direction of FDI, promote FDI to weaker industries and backward economic development area. It is beneficial not only to promote urbanization, but also expand opening level of all kinds of industries such as agriculture, forestry and fishery, hence increasing farmers' income, and developing the economic.

In contrast, the effect of foreign investment to economic growth experiences a slight decline at first, this may be the foreign investment stage has negative effect to the domestic industry in initial. it falls volatility to convergence after rising gradually, meaning that foreign investment shows weakened state in China's economic growth gradually. Therefore, the government should strengthen the legal construction in the early period, standardize the order of the market to create a fairness and justice environment for domestic and foreign enterprises. In the process of the gradual development of economy, we should safeguard the legitimate rights and interests of all multinational companies in China and establish a set of market management system accepted internationally to enhance the confidence of foreign investors. Meanwhile, we should relax restrictions on foreign investment, and give appropriate encouragement.

For the influence of foreign investment to the urbanization, it does not change significant early, while grow dramatically afterwards. This shows that overall level of foreign investment in our country is not high, the advantage of foreign investment is still not fully revealed. But in general, in the process of both short-term and long-term, the impact of foreign investment to urbanization is rising, showing that foreign investment has positive influence on the propulsion of urbanization. Thus, we strongly recommend that relevant departments should actively focus on the foreign investment and the transformation government function, for further straighten out the relationship between management and service. We should perfect the related infrastructure construction, strengthen the cultivation of cultural identity and transfer competitive advantage of industry agglomeration into urban competitiveness in order to better promote the economic development and attract foreign investment.

\section{Reference}

Hein, S. (1992). Trade strategy and the dependency hypothesis[J]. Economic Development and Cultural Change, 40(3), 495-521.

Kasarda, J. D., Crenshaw, E. M. (1991). Third world urbanization: dimensions, theories, and determinants[J]. Annual Review of Sociology, 17(17), 467-501.

The state statistical bureau. China statistical annual[J]. Beijing: China statistics press, 1999-2015.

Wang, L. (2011). Study based on VAR model about relationship between population urbanization and economic growth: Based on 1978-2009 data of Shanghai[J]. Journal of international trade, 9, 65-74.

Yue, C. S. (1993). Foreign Direct Investment in ASEAN[M]. Kuala Lumpur: Malaysian Economy Association,

\section{(c) EY}

This work is licensed under a Creative Commons Attribution 3.0 License. 